\title{
Effects of Social Realism, Loyalty, and Collective Polarization in Moodle-based Online Learning on College Students' Online Learning Motivation
}

\author{
Eun Joo Kim \\ Eulji University, Geonggido, South Korea \\ kej70@eulji.ac.kr
}

\begin{abstract}
This study analyzes the impact of social realism, loyalty, and group polarization triggers on online learning motivation in college students in online learning. This aims to provide basic data on how to ensure the quality of education in an online educational environment by selecting a predictor that influences the online learning motivation as a sense of social reality, loyalty, and collective polarization. To this end, a study was conducted on 83 students from the four-year E University in Gyeonggi-do. The research method conducted a mid-regression analysis to determine which of the sub-factors of social realism, loyalty, and group polarization is the most influential variable for online learning motivation, and to identify which model is most suitable to explain online learning motivation. Studies have shown, first, that loyalty in online learning is a predictor that motivates college students to learn. Second, mutual support and concentration of social realism in online learning are predictors that induce motivation for college students to learn. Third, perceptual bias in group polarization-inducing nature in online learning is a predictor that triggers learning motivation in college students. Fourth, in online learning, my group co-operation in group polarization-inducing nature is a predictor that hinders college students' motivation to learn.
\end{abstract}

Keywords: Online learning, Social realism, Loyalty, Collective polarization, Learning motivation

\section{Introduction}

The development of information and communication technology has led to the expansion of online learning in the educational field. In particular, due to the COVID-19 pandemic in 2020, educational institutions around the world have compulsively introduced online courses without prior preparation for non-face-to-face classes. Such a social emergency has brought a shift in perception among teaching methods in the future. In addition to these social changes, most students in the current era are digital native generations; there has been an interest in educational changes in teaching methods considering the learning motivation of learners who are familiar with online learning rather than offline learning. Such changes can be handled through continuous learning [1], which enables the modification and development of existing learning and experiences suitable for reality. It is not easy to enhance the motivation to learn which makes continuous learning possible in online learning environments (compared to traditional classroom education). In online learning, compared to traditional classroom

Article history:

Received (May 5, 2021), Review Result (June 9, 2021), Accepted (July 20, 2021) 
learning, the degree of active participation of learners determines the effectiveness of learning, and thus, plans are needed to revitalize the motivation to learn that encourages learners to continuously participate in courses. Such plans should consider the learning environment, learning tasks, and characteristics of learners [2].

In an online communication environment with high anonymity, an individual perceives the identity of the online group that they belong to like their own identity. In addition, they show the tendency of following the behavior patterns of the groups [2]. These characteristics can trigger group polarization in online learning. Group polarization is a significant predictive factor for learning motivation; there are cases in which individuals make more biased decisions in social media or online environments than in personal circumstances. Online debate learning can enhance learning motivation as learners can trigger positive group polarization. In addition, Shim (2013) confirmed that group polarization influenced online learning motivation [3].

Furthermore, as a result of the analysis on the structural relationship between learner's loyalty and learning motivation in online learning, it was confirmed that there was a significant positive correlation between learner's learning motivation and online learning loyalty [4]. In online learning, loyalty refers to favorable behavior by continuously using education services. In other words, it refers to the learners' attitude and intention toward the services: their attitude, belief, and will, including their intention to continuously attend classes or a recommendation of classes to peers [5][6]. As such, it is predicted that learning participation activities in online learning environments will become no different from those in offline learning environments. It is more important for learners to participate in online learning with loyalty, rather than focusing on the distinction between the physical environment online and offline.

Therefore, with an independent variable that can affect online learning motivation, this study is designed to analyze the effects of social presence and group polarization on online learning motivation in Moodle-based online learning. This has been conducted in line with the recent changes in the online learning educational environment.

\section{Research method}

\subsection{An object of study}

Table 1. General characteristic $(\mathrm{N}=83)$

\begin{tabular}{|c|c|c|c|}
\hline \multicolumn{2}{|c|}{ Observational variable } & Frequency & $\%$ \\
\hline \multirow{3}{*}{ Gender } & Male & 44 & 53.0 \\
\cline { 2 - 4 } & Female & 39 & 47.0 \\
\hline \multirow{3}{*}{ Grade } & 2 & 13 & 15.7 \\
\cline { 2 - 4 } & 3 & 51 & 61.4 \\
\cline { 2 - 4 } & 4 & 19 & 22.9 \\
\hline \multirow{3}{*}{ A previous semester's rating } & $1.5 \sim 2.5$ & 17 & 20.5 \\
\cline { 2 - 4 } & $2.5 \sim 3.0$ & 14 & 16.9 \\
\cline { 2 - 4 } & $3.0 \sim 4.0$ & 41 & 49.4 \\
\cline { 2 - 4 } & 4.0 & 11 & 13.3 \\
\hline
\end{tabular}

\subsection{Measuring instrument}

To measure the social presence, a tool developed by Kim (2009) was used, and the subfactors (i.e., emotional bond, open communication, community feeling, mutual support, and 
concentration) consisted of a total of 15 questions [7]. The overall inter-item consistency of the questionnaire items was $\alpha=.903$, indicating good reliability. As for the loyalty measurement tool, questionnaire items used in the studies of Kang (2000) (based on Koh's (2000) research) were used. This tool consists of three questions about continuous participation [8-9], proorganizational behavior, and word-of-mouth behavior. The overall inter-item consistency of the items was $\alpha=.911$, indicating good reliability. A measurement tool for group polarization was employed, which was first developed by $\mathrm{Na}$ and $\mathrm{Cha}$ (2012) and then was confirmed for its validity by Shim (2013) [3][11]. The subfactors for group polarization consist of a total of 12 questions regarding outgroup exclusion, exclusion-conforming behavior, inter-group synchronization, and perceptual bias. The overall inter-item consistency of the questionnaire items was $\alpha=.908$, indicating good reliability. The values of the variables for each question were based on the 5-point Likert scale: 'Very Low' (1 point), 'Low' (2 points), 'Normal' (3 points), 'High' (4 points), and 'Very High' (5 points).

\subsection{Data analysis}

The PASW Statistics 18.0 program was used to analyze the data collected to explore the research questions. Frequency and percentage analysis were conducted to examine the subjects' general characteristics, and Cronbach's alpha coefficients were calculated to determine the internal fit of the research tools. A descriptive statistics analysis was conducted to examine the means and standard deviations of online learning motivation, social presence, loyalty, and group polarization. In addition, a multiple regression analysis was performed to identify which variables among the sub-factors of social presence, loyalty, and group polarization have the greatest influence on online learning motivation, and to identify the most appropriate model to explain online learning motivation. A stepwise method was used to select variables to be included in the most appropriate regression model.

This method is the most commonly used; when adding variables one by one, the significance of each existing variable in the model is tested; if it is not significant, it is removed from the model. In addition, to increase the predictive power of the multiple regression equation, there should be a high correlation between dependent variables and each independent variable, as well as a low correlation between independent variables. In other words, tolerance and variance inflation factor (VIF) were calculated to identify multicollinearity between independent variables. When both tolerance and VIF are close to 1 , it is judged that there is no multicollinearity. If VIF is more than 10, multicollinearity is strongly suggested. The maximum tolerance limit was .994 and the VIF was 6.106, indicating that the correlation between independent variables was not high enough to cause problems. In other words, both tolerance and VIF met the basic assumptions for the multiple regression analysis.

\section{Result and analysis}

\subsection{The descriptive statistics on social presence, loyalty, group polarization, and online learning motivation}

Table 2. Descriptive statistics on social presence, loyalty, group polarization, and online learning motivation $(\mathrm{N}=83)$

\begin{tabular}{|c|c|c|c|}
\hline \multicolumn{2}{|c|}{ Category } & M & SD \\
\hline \multirow{2}{*}{ Social Presence } & Emotional bond & 4.02 & .802 \\
\cline { 2 - 4 } & Open communication & 4.07 & .762 \\
\hline
\end{tabular}




\begin{tabular}{|c|c|c|c|}
\hline & Community feeling & 4.19 & .744 \\
\cline { 2 - 4 } & Mutual support and concentration & 4.21 & .798 \\
\hline \multirow{3}{*}{ Group Polarization } & Outgroup exclusion & 2.43 & 1.156 \\
\cline { 2 - 4 } & Exclusion-conforming behavior & 2.24 & 1.094 \\
\cline { 2 - 4 } & Inter-group synchronization & 2.86 & 1.078 \\
\cline { 2 - 4 } & Perceptual bias & 2.74 & 1.025 \\
\hline & Loyalty & 4.05 & .750 \\
\hline
\end{tabular}

As for a result of the descriptive statistics of online learning motivation, social presence, loyalty, and group polarization, the average (standard deviation) of mutual support and concentration shows the highest value of 4.21 (.798) among sub-factors of social presence. The average (standard deviation) of inter-group synchronization shows the highest value of 2.86 (1.078) among sub-factors of group polarization. The average (standard deviation) of loyalty is 4.05 (.750), and that of online learning motivation is $4.12(.678)$.

\subsection{Statistical significance for a model measuring the influence of social presence, loyalty, and group polarization factors on online learning motivation}

Table 3. Analysis of variance $(\mathrm{N}=83)$

\begin{tabular}{|c|c|c|c|c|c|}
\hline & Sum of squares & df & Mean square & F & $p$ \\
\hline Regression Model & 27.045 & 4 & 6.761 & 49.512 & $.000 f$ \\
\hline Residual & 10.651 & 78 & .137 & & \\
\hline Total & 37.696 & 82 & & & \\
\hline \multicolumn{7}{|c|}{ R2 (adj. R2) $=.717(.703)$} \\
\hline
\end{tabular}

The following are the results of statistical significance testing for the model that measures online learning motivation of college students with independent variables of social presence, loyalty, and group polarization. Social presence's sub-factors (i.e., emotional bond, open communication, community feeling) and group polarization's sub-factors (i.e., outgroup exclusion and exclusion-conforming behavior) were excluded due to non-significance. In the model with the other social presence sub-factors (i.e., mutual support and concentration) and the other group polarization's sub-factors (i.e., inter-group synchronization, loyalty, and perceptual bias) were significant, with the F-statistic being 49.51 and the probability of significance as .000. The independent variables included in the model demonstrated significance with online learning motivation with a significance level of .05. Seventy-one percent of the total change in online learning motivation ( $70 \%$ according to the modified decision coefficient) is related to the independent variables contained in the model.

3.3. The influence of social presence, loyalty, and group polarization factors on online learning motivation

Table 4. Multiple regression analysis on online learning motives $(\mathrm{N}=83)$

\begin{tabular}{|c|c|c|c|c|c|}
\hline \multirow{2}{*}{ Independent variable } & \multicolumn{2}{|c|}{$\begin{array}{c}\text { Unstandardized regression } \\
\text { coefficients }\end{array}$} & $\begin{array}{c}\text { Standardized } \\
\text { regression coefficients }\end{array}$ & $\mathrm{t}$ & $\mathrm{p}$ \\
\cline { 2 - 5 } & $\mathrm{B}$ & Standard error & & 2.506 & .014 \\
\hline (constant) & .777 & .310 & .475 & 6.987 & .000 \\
\hline loyalty & .430 & .062 & & & \\
\hline
\end{tabular}




\begin{tabular}{|c|c|c|c|c|c|}
\hline $\begin{array}{c}\text { inter-group } \\
\text { synchronization }\end{array}$ & -.368 & .060 & -.584 & -6.117 & .000 \\
\hline perceptual bias & .361 & .063 & .546 & 5.762 & .000 \\
\hline $\begin{array}{c}\text { mutual support and } \\
\text { concentration }\end{array}$ & .394 & .059 & .463 & 6.665 & .000 \\
\hline
\end{tabular}

The contribution of each independent variable to the dependent variable was tested at the significance level of .05 to determine statistical significance. The independent variables which significantly influence online learning motivation are loyalty $(\mathrm{t}=6.98, \mathrm{p}=.000)$, inter-group synchronization $(\mathrm{t}=-6.11, \mathrm{p}=.000)$, perceptual bias $(\mathrm{t}=5.76, \mathrm{p}=.000)$, and mutual support and concentration ( $\mathrm{t}=6.66, \mathrm{p}=.000)$. According to the standardization coefficient (indicating the relative contribution of independent variables), the variables of inter-group synchronization, perceptual bias, loyalty, and mutual support and concentration influence online learning motivation in this particular order. The corresponding regression equation is as follows.

Online learning motivation $=.777+.430$ (loyalty) -.368 (inter-group synchronization) +.361 (perceptual bias) +.394 (mutual support and concentration)

Therefore, it was found that loyalty, perceptual bias, and mutual support and concentration had a positive effect on the motivation to learn online, whereas inter-group synchronization harmed the motivation to learn online. In other words, the enhancement of online learning motivation requires higher loyalty, the improvement of perceptual bias (a sub-factor of group polarization), and mutual support and concentration (a sub-factor of social presence), without triggering inter-group synchronization in online learning environments [12][13][14].

\section{Conclusion and discussions}

This study analyzed the effects of social presence and group polarization on online learning motivation in a Moodle-based online learning format for college students. As a result, it was found that loyalty, perceptual bias, and mutual support and concentration had a positive effect on online learning motivation, while inter-group synchronization harmed motivation. In conclusion, it was found that in a Moodle-based online learning format, loyalty, mutual support and concentration (a sub-factor of social presence), and perceptual bias (a sub-factor of group polarization) had a positive influence on college students' motivation to learn. Yet it was found that inter-group synchronization (a sub-factor of group polarization) showed a negative influence.

Therefore, the research results have drawn the following implications.

First, in online learning environments, loyalty was found to be a predictive factor to encourage the motivation to learn for college students. Therefore, online learning should be designed for learners to lead their beliefs and attitudes.

Second, in online learning, mutual support and concentration (a sub-factor of social presence) was found to be a predictive variable that encourages the motivation to learn for college students. This study shows that it is important that learners feel that they are connected with their fellow learners in an online learning environment [14]. When learning processes are designed for online learning, it is necessary to consider that learners should be able to facilitate interaction.

Third, a perceptual bias of group polarization was found to be a predictive variable inducing the motivation to learn for college students in an online learning environment. Therefore, when 
designing online classes, instructors should create online learning communities and provide teaching methods to share information between students, as well as between students and professors in online communities.

Fourth, inter-group synchronization of group polarization was found to be a predictive variable that hinders the motivation to learn for college students in an online learning environment. Therefore, this study implies that free and tolerant debate classes should be conducted so that biased opinions on specific issues do not exist when opinion sharing occurs between students, as well as between professors and students during online classes.

As such, with predictive variables that influence the motivation to learn for college students in a Moodle-based online learning environment, this study has great implications for education in the post-coronavirus era. Nevertheless, there are limitations. First, this study is only based on one university in which the data was collected. Therefore, it is necessary to conduct research that can represent the characteristics of the population using large-scale data in subsequent studies. Second, in addition to the independent variables set in this study, it is necessary to explore other various independent variables that may affect learners' motivation to learn in an online learning environment and to analyze the influence and structural relationship between these variables. The educational field has experienced numerous changes since the COVID-19 pandemic. Through follow-up studies, it should be possible to prevent the decline in education quality in an online learning environment.

\section{Reference}

[1] J. Park, "The effect of 'self-growth group counseling' on the self-efficacy and self-identity of adult learners at lifelong learning-centered university," Journal of Learner-Centered Curriculum and Instruction, vol.15, no.5, pp.545-567, (2015)

[2] H. Han, "The effect of learning motivation on self-efficacy and usefulness in online IT education," Hankuk University of Foreign Students Doctoral Thesis, (2013)

[3] J. Shim, "A study on the effects of SNS uses on group polarization-with the concept of network homogeneity," Hankuk University of Foreign Students Master's Thesis, (2013)

[4] H. Jeong, "A structural analysis of the relationship among adult learners' learning motivation," Learning Engagement, and Course Loyalty to Mobile Based Online Courses," Journal of Lifelong Learning Society, vol.12, no.1, pp.117-144, (2016)

[5] R. J. Brodie, A. Ilic, B. Juric, and L. Hollebeek, "Consumer engagement in a virtual brand community: An exploratory analysis," Journal of Business Research, vol.66, no.1, pp.105-114, (2013)

[6] C. M. Sashi, "Customer engagement, buyer-seller relationships, and social media," Management Decision, vol.50, no.2, pp.253-272, (2012)

[7] J. J. Kim, "Development of a scale to measure social presence in distance higher education," Korea University Doctoral Thesis, (2009)

[8] S. U. Kang, "The effect of sense of virtual community on member's site loyalty: Using the flow," Sogang University Master's Thesis

[9] J. Koh, "Psychological states and behavior in virtual communities: Typology and empirical validation," A dissertation proposal for the degree of Doctor of Philosophy in the Korea Advanced Institute of Science and Technology, (2000)

[10] [10] E. Y. Na Eun and Y. R. Cha, "Determinants of internet group polarization: Effects of anonymity and network crowdedness of internet public sphere, and individual and cultural factors," The Korean Journal of Social and Personality Psychology, vol.26, no.1, pp.103-121, (2012)

[11] S. H. Lee, "The effects of social presence on students' learning flow, satisfaction, and learning intention in online education of universities.," Journal of Hotel and Resort, vol.20, no.2, pp.221-240, (2021) 
[12] Seoul Journal (2021.03.10), A year of non-face-to-face classes, Students in the remote shade, https://www.seoul.co.kr/news/newsView.php?id=20210311010011\&wlog_tag3=naver

[13] K. Lee, "A study on the social presence of international students in real-time online classes and group activities," The Journal of Learner-Centered Curriculum and Instruction, vol.21, no.6, pp.547-563, (2021)

[14] J. J. Lee, “A study on the relations among tutors' roles perceived by learners, social presence, and learning outcomes in web-based online discussions," Ewha Womans University Master's Thesis, (2010)

\section{Authors}

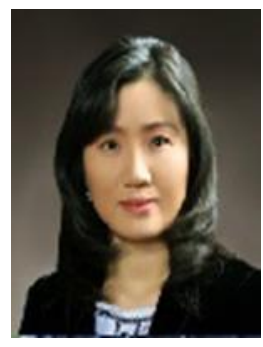

Eun Joo Kim, Ph.D.

Professor of Liberal Art at Eulji University, Korea. She is a graduate of the Department of Education at Kookmin University in Korea, and the interesting areas of research are managing the quality of education such as learners' learning experience, learning performance, and education evaluation, creativity education. 
Effects of Social Realism, Loyalty, and Collective Polarization in Moodle-based Online Learning on College Students' Online Learning Motivation

This page is empty by intention. 